\title{
Sustainable application of magnesium alloy through Electrodeposition of Hydroxyapatite Coating
}

\author{
Motilal Lakavat ${ }^{1 *}$ Isaac Ramalla ${ }^{2}$ and G Praveen kumar $^{2}$ \\ ${ }^{1}$ Caledonian College of Engineering Muscat, P.O.Box: 2322, CPO Seeb 111, Sultanate of Oman, \\ ${ }^{2}$ Department of Electrical Engineering, University of Petroleum and Energy Studies, Bidholi Campus, \\ Dehradun,
}

\begin{abstract}
Magnesium (Mg) and its alloy are potential material for biodegradable implants which makes promising due its mechanical properties. However, corrosion of these metals alloys is too quickly results in losing mechanical integrity. The problem had risen in scientific committee to solve/reduce the corrosion rate and enhance the biocompatibility of the Mg-alloy. In order to reduce the corrosion, surface was modified with the hydroxyapatite (HAp) coating. The synthesis of HAp on Mg-alloy substrate was carried out by an electrodeposition method i.e., chemical deposition. The post treatment of deposited HAp on Mg-alloy with alkali solution which results in electrodeposited calcium hydrogenphosphate coatings into the bone-like hydroxyapatite coatings. Cyclic voltammetry and electrochemical impedance spectroscopy was studied to determine the barrier properties of the HAp coatings. Polarization test in a Hanks' solution was investigated to sense the protectiveness of the coatings, which is critical for better in-service mechanical integrity. The existence of the HAp coating and its morphology on Mg-alloy was verified using Fourier transform infrared spectroscopy (FTIR).
\end{abstract}

Keywords: Mg-alloy, hydroxyapatite coating, mechanical integrity, biocompatibility.

\section{Introduction}

Magnesium alloys have excellent specific strength and stiffness, exceptional dimensional stability, high damping capacity, and high recycle ability[1-4]. Based on these superior properties and a combinative requirement for reducing environmental burdens by using light weighted structures, the research and development of magnesium alloys for practical industrial application have overwhelmingly increased worldwide during the past decade. Magnesium and its alloys are becoming widely recognized as playing an increasingly important role in automotive, aircraft, and electronic consumer products [5-7].

Magnesium (Mg), by virtue of its desirable mechanical properties, non-toxicity, and degradability, is a potential candidate metallic material for degradable implants. Biodegradable implant materials in the human body can be gradually dissolved, absorbed, consumed or excreted, so there is no need for the secondary surgery to remove implants after the surgery regions have healed[8-10]. Currently, degradable implants are made of polymer materials. Owing to the low mechanical strength, polymeric implants are used only in low load-bearing applications[11,12]. Thus the development of high load-bearing degradable orthopedic implants is an attractive idea for bone fracture healing. According to a recent review by Staigeret. al, the mechanical properties of $\mathrm{Mg}$ are close to those of bones, and $\mathrm{Mg}$ is non-toxic and excess of $\mathrm{Mg}$ in human body can be easily excreted via urine[13].

Magnesium alloys can be divided into cast magnesium alloys and wrought magnesium ones in terms of difference in processing. Main commercial magnesium alloys include the AZ series ( $\mathrm{Mg}-\mathrm{Al}-\mathrm{Zn}$ ), AM series (Mg-Al-Mn), AE series (Mg-Al-RE), EZ series (Mg-REZn), ZK series (Mg-Zn-Zr), and WE series (Mg-RE-Zr). Statistically, more than $90 \%$ of the magnesium alloy structural components are produced by casting process, especially by various die-casting processes[13-15]. In the last decade, the AZ series cast magnesium alloys, especially the AZ91 alloy, have been extensively studied and used for some structural components of automobiles, aircraft, and computers, because of high specific strength and good cast ability [16]. Compared with cast magnesium alloys, wrought magnesium alloys have a more promising perspective of application, which is the reason why research and development of high performance wrought magnesium alloys, novel wrought magnesium processing technology, and producing high quality wrought magnesium alloy products are an important objective. A long time research plan of wrought magnesium alloys was put forward by the international magnesium association (IMA) in 2000[17]. In recent years, the research on wrought magnesium alloys is increasingly attracting the attention of companies and researchers[18-21].

Many methods such as plasma spraying, pulse laser melting, and physical vapor deposition cannot be used to deposit HA coating on Mg-alloy because of its low melting point and poor heat resistance. Electrochemical deposition has unique advantages due to its capability of forming uniform coating and simple setup. In addition, the deposition processing can be conducted at room temperature and the morphology of 
coating can be controlled easily by varying the electrochemical potential and other parameters. In this paper we report the preparation of hydroxyapatite (HAp) coatings on magnesium Mg-alloy by electrodeposition and subsequent treatment in alkaline $(\mathrm{NaOH})$ solution and by an alternative immersion method (AIM)[22-25]. The barrier properties of the coatings in the Hanks' solution were investigated using electrochemical impedance spectroscopy (EIS) and voltammetry methods. Morphology of the HAp coatings was studied using Fourier transform infrared spectroscopy (FTIR)[26-28].

\section{Experimental}

Cylindrical shaped electrodes having surface area $0.235 \mathrm{~cm} 2$, in a glass tube and working electrode with Mg-alloy composition of $8.6 \mathrm{Al}, 0.51 \mathrm{Zn}, 0.19 \mathrm{Mn}, 0.05 \mathrm{Si}, 0.025 \mathrm{Cu}, 0.004 \mathrm{Fe}$ and remaining $\mathrm{Mg}$. Electrodes are polished with alumina powder of $0.05 \mu \mathrm{m}$, in ethanol in ultrasonic bath, rinsed with distilled water, kept immersed in $1.0 \mathrm{M}$ solution of $\mathrm{NaOH}$ at $80{ }^{\circ} \mathrm{C}$ for $1 \mathrm{~h}$, and finally rinsed with distilled water. Electrodeposition of HAp was carried out at constant potential values of $-2.0 \mathrm{~V}$ for different periods of time in a solution $\left(100 \mathrm{~cm}^{3}\right)$ containing $50 \mathrm{~cm}^{3} 0.1 \mathrm{~mol} \mathrm{dm}{ }^{-3} \mathrm{Ca}(\mathrm{NO} 3)_{2}$ and $0.06 \mathrm{~mol} \mathrm{dm}{ }^{-3} \mathrm{NH}_{4} \mathrm{H}_{2} \mathrm{PO}_{4}$. The pH of the solution was adjusted with $0.5 \mathrm{~mol} \mathrm{dm}^{-3} \mathrm{HNO}_{3}$ to 5 . The hanks solution was used to test the corrosion resistance of HAp at $37^{\circ} \mathrm{C}$. All chemicals were of p.a. purity.

Hanks solution experiment was carried out in standard three-electrode cell captaining $100 \mathrm{cc}$ of solution. The counter electrode was a large area platinum electrode and the reference electrode, to which all potentials are referred, was an $\mathrm{Ag} / \mathrm{AgCl} / 3 \mathrm{M} \mathrm{KCl}(209 \mathrm{mV}$ vs. SHE). Potentiometric measurements were performed at a sweep rate of $10 \mathrm{mV} \mathrm{s}^{-1}$. Electrical open circuit potential (EOCP) was measured in the frequency range from $100 \mathrm{kHz}$ to $0.1 \mathrm{~Hz}$ with an $\mathrm{AC}$ signal $\pm 5 \mathrm{mV}$. SolartronZView ${ }^{\circledR}$ software was used to fit the Impedance data of suitable electrical equivalent circuit (EEC) model, employing the complex non-linear least squares (CNLS). The HAp deposit was characterized by FTIR. The FTIR spectra were recorded in the 4000$650 \mathrm{~cm}^{-1}$ region with the scan resolution of $4 \mathrm{~cm}^{-1}$ using Horizontal Attenuated Total Reflectance (HATR) method on a Perkin-Elmer spectrum one FTIR spectrometer.

\subsection{Electrochemical deposition of hydroxyapatite}

\section{Results and Discussion}

Electrodeposition of hydroxyapatite film was performed using Modification of the electrodes at room temperature in a solution $\left(100 \mathrm{~cm}^{3}\right)$ containing $50 \mathrm{~mL} 0.1 \mathrm{~mol} \mathrm{dm}{ }^{-3} \mathrm{Ca}\left(\mathrm{NO}_{3}\right)_{2}$ and $50 \mathrm{ml} 0.06 \mathrm{~mol} \mathrm{dm}^{-3}$ $\mathrm{NH}_{4} \mathrm{H}_{2} \mathrm{PO}_{4}$ which is having a $\mathrm{pH} 5$ at constant potential value of $-2.0 \mathrm{~V}$. The electrodeposition time was chosen between 30 to $180 \mathrm{~min}$.Reactions on the surface of $\mathrm{Mg}$-alloy during electrodeposition are known as Step I: reduction of the hydrogen from $\mathrm{H}_{2} \mathrm{PO}^{4-}$ and $\mathrm{HPO}_{4}{ }^{2-}$ and Step II: $\mathrm{Ca}^{2+}$ ion reacts with $\mathrm{HPO}_{4}{ }^{2-}$ and $\mathrm{PO}_{4}{ }^{3-}$ and form $\mathrm{CaHPO}_{4} \times 2 \mathrm{H}_{2} \mathrm{O}$ and $\mathrm{Ca}_{3}\left(\mathrm{PO}_{4}\right)_{2}$. Brushite and $\beta-\mathrm{TCP}$ are the precursors to the more stable phase hydroxyapatite, $\mathrm{Ca}_{10}\left(\mathrm{PO}_{4}\right)_{6}(\mathrm{OH})_{2}$, HAp. Alkaline treatment (acid-base reaction) converts brushite and $\beta$-TCP film formed on the Mg-alloy surface by electrodeposition into hydroxyapatite, HAp.These results clearly show that electrodeposited coating prior to alkaline treatment is mainly consisted of calcium phosphate dihydrate and $\beta$-TCP. Alkaline treatment results in the HAp coating formation.Prior investigations have also utilized the increased solubility of brushite on metallic implants as a means of increasing the amounts of calcium and phosphate ions available in the immediate vicinity of the implant to promote increased osseo-integration.

\subsection{Barrier properties of the coating}

Nyquist plot for various frequency dispersions (a) for an ideally capacitive behavior of plainelectrodes; (b) for the in-a-pore dispersion simulated by de-Levie's standard equation (c) for the in-a-pore dispersion and by pore size distribution simulated by TLM-PSD. The impedance of most electrodes deviates from the purely capacitive behavior which isrepresented as a vertical line in the Nyquist plot, curve (a) in Figure 1

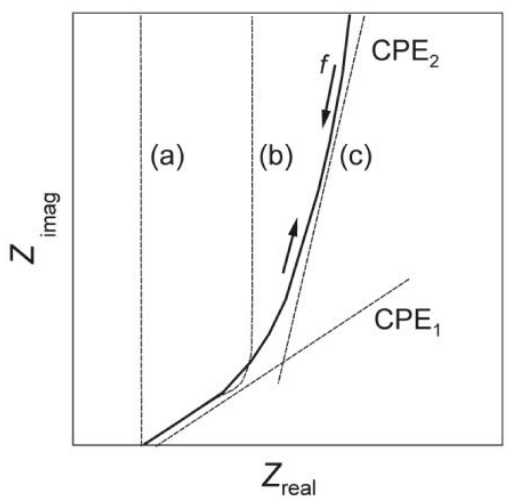

Figure 1 Nyquist plot of various frequencies to compare the ideal behavior 


\subsection{Electrochemical impedance spectroscopy}

From the figure 1, it is describe that $C P E_{1}$ at high frequencies and with an ideal capacitance at low frequencies while curve (c) can be approximated with the $C P E_{1}$ at high frequencies and roughly with the $C P E_{2}$ at low frequencies. Frequency dispersion leads to an inclined line whose phase angle is equal to $(\pi / 2) \mathrm{n}$. The empirical distributed element was used to describe the non-ideality due tofrequency dispersions by the constant phase element $(C P E)$. Its impedance is equal to ZCPE $=[Q-(j \omega) n]-1$, where $Q$ is the frequency independent parameter, $\omega$ is the angular frequency, and $\mathrm{n}$ is the $C P E$ power. When $\mathrm{n}=1, Q$ represents the pure capacitance, while for $n \neq 1$ the system shows behavior that has been attributed to the surface heterogeneity, or to the continuously distributed time constants for charge transfer reactions.

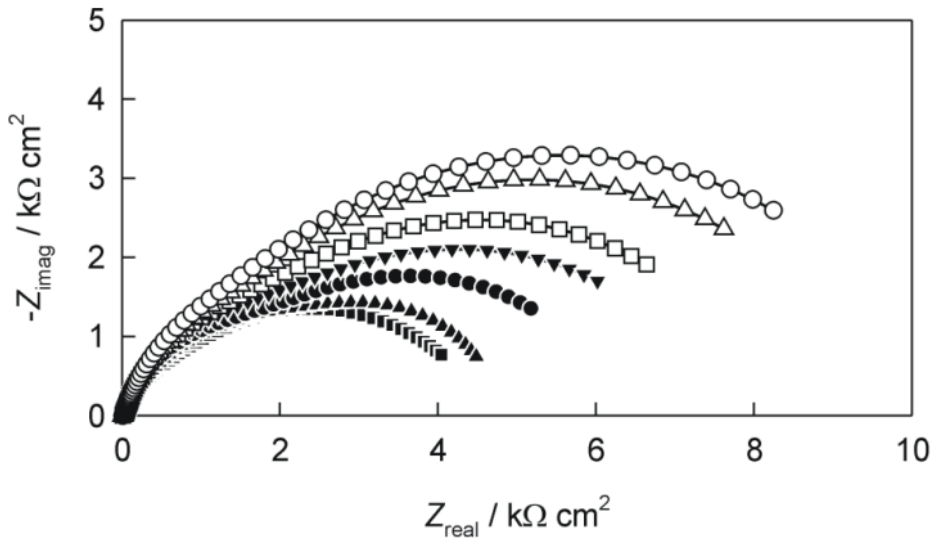

Figure 2. Nyquist and Bode plots for the impedance data for uncoated $\mathrm{Mg}$-alloy

Nyquist and Bode plots for the impedance data recorded with uncoated Mg-alloy (with a native surface layer) and $\mathrm{HAp}$ coated $\mathrm{Mg}$-alloy in the Hanks' solution $\left(37^{\circ} \mathrm{C}\right)$ at $E_{\mathrm{OCP}}$. Electrodeposition was performed at $-2.0 \mathrm{~V}$ for denoted time periods. Corrosion resistance of $\mathrm{Mg}$-alloy unmodified and modified with a hydroxyapatite (HAp) film in the Hanks' solution was investigated by EIS. Figure 2 shows the Nyquist and Bode plots ofimpedance spectra of unmodified and with HAp film modified Mg-alloy recorded in Hanks'solution at open circuit potential after $30 \mathrm{~min}$ of stabilization. The Nyquist plot for unmodified Mg-alloy show flattened capacitive semicircle with the canter below the real axis.

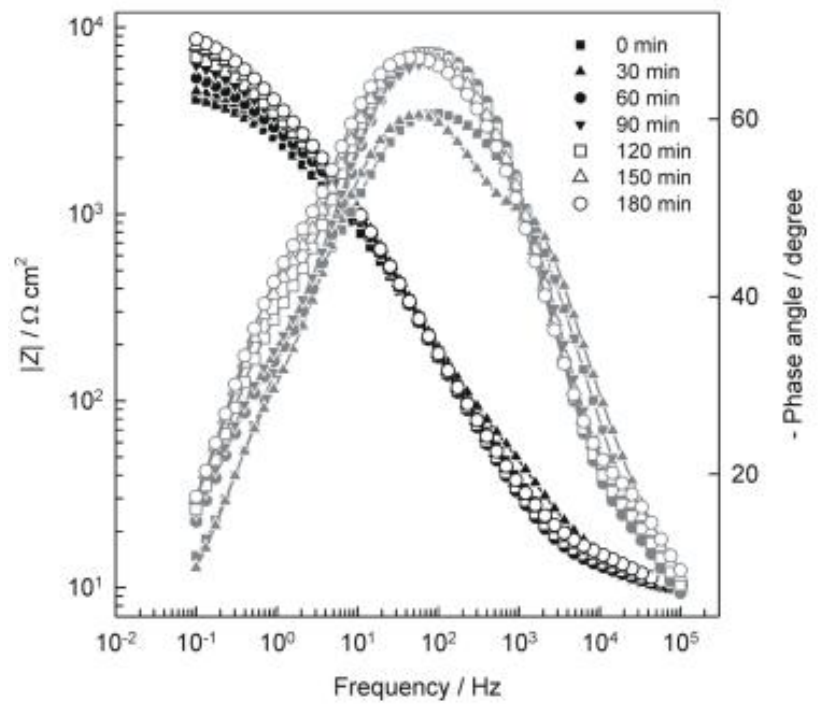

Figure 3. Nyquist and Bode plots for the impedance data of Mg-alloy

The overall impedance of modified Mg-alloy was plotted with Nyquist for coated withhydroxyapatite was significant compared to unmodified $\mathrm{Mg}$-alloy. Electrodeposition time of modified $\mathrm{Mg}$-alloy was significant as shown using capacitive semicircle increase. The presence of hydroxyapatite was observed in low frequency region of bode plot. The value of $\log |Z|$ is significant at which dominates the polarization resistance. EIS data recorded for the unmodifiedMg-alloy in Hanks' solution was modelled by the electrical equivalent circuit (EEC) with two timeconstants. 
In the EEC, constant phase element $C P E_{1}$ attributed to the double layercapacitance, and $R_{1}$ to the charge transfer resistance and $C P E_{2}$ and $R_{2}$ attributed to the resistance of thefilm and capacitance of the ions travel through the film. In the case of electrodes modified withhydroxyapatite at low frequency region of the impedance spectra an additional time constant appears.It is attributed to the diffusion processes and described by the Warburg diffusion element $W \mathrm{~s}$. The total impedance, $Z$ of the investigated electrochemical system is the sum of the ohmic resistanceand the impedance of the electrochemical interface $(Z \mathrm{el}+Z \mathrm{HF}+Z \mathrm{LF})$ and is described by the transferfunction:

$$
Z(j \omega)=R_{e l}+\left\{Q_{1}(j \omega)^{n_{1}}+\left\{R_{1}+\left[Q_{2}(j \omega)^{n_{2}}+\left(R_{2}+Z_{W}\right)^{-1}\right]^{-1}\right\}^{-1}\right\}^{-1}
$$

The sum of $\mathrm{R}_{1}$ and $\mathrm{R}_{2}$ represent the polarization, resistance and a diffusional resistance $\left(R_{1}-\mathrm{R}_{2}\right)$. Electrodeposition of hydroxyapatite affects the corrosion behavior which was observed during the experiment, i.e, polarization resistance of the Mg-alloy in Hanks' solution. The value ofpolarization resistance increases with an increase of the electrodeposition time. Electrochemical double layer capacitance decreases with increases of theelectrodeposition time.

Therefore, the EEC includes also the so-called "O"circuit element ("porous bounded Warburg"). The term "O" represents a dimensional diffusion througha layer of finite thickness or the (penetrability) penetration depth of the $A C$ signal across pores of finitelength.The impedance parameters of uncoated $\mathrm{Mg}$-alloy and $\mathrm{Mg}$ alloy samples coated withHAp coatings, obtained in Hanks' solution $\left(37^{\circ} \mathrm{C}\right)$ at $E \mathrm{OCP}$. Electrodeposition was performed at-2.0 $\mathrm{V}$ for denoted time periods.

\subsection{Polarization measurements}

Polarization curves measurements were recorded with uncoated and HAp coated alloy specimens, using a scan rateof $10 \mathrm{mV} \mathrm{s}^{-1}$, are shown in Figure 3. It is observed that polarization curve for all specimens'exhibits a linear Tafel region with slope values ranging from $-235 \mathrm{mV} \mathrm{dec}^{-1}$ to $-140 \mathrm{mV} \mathrm{dec}^{-1}$ at cathodic branch of cell. This is similar observation as in case of hydrogen evolution reaction, which occurs atelectrodes covered with a surface film The values obtained agree well with those reported forMg-alloys that were unmodified and modified with SAMs of fatty acids or phosphonate SAMs, andimmersed in near neutral aqueous solutions containing chloride ions. The hydrogen dissolution at anodic region i.e, simultaneous combination of both anodic dissolution and localized corrosion has been reported for reason of complicated anodic polarization behavior of unprotected Mg-alloy. Figure 4, shows at different times the deposition of HAp at cathodic and anodic electrodes.

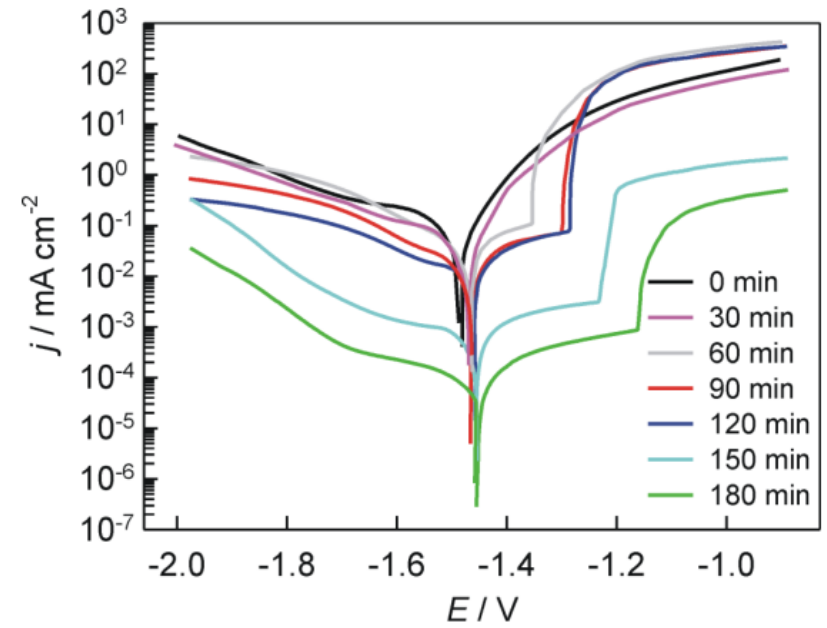

Figure 4 Tafel plots recorded with uncoated Mg-alloy

Tafel plots recorded with uncoated Mg-alloy (with a native surface layer) and HApcoated Mg-alloy in the Hanks' solution at $37^{\circ} \mathrm{C} ; v=10 \mathrm{mV} \mathrm{s}^{-1}$. It can be observed from the Figure 4, that Electrodeposition wasperformed at $-2.0 \mathrm{~V}$ for denoted time periods. The rate determining for corrosion process of all specimens are indicated around $E_{\text {corr }}$ by the cathodic and anodic portions of the polarization curves. Extrapolation of thelinear part of the cathodic currents to the corrosion potential was use for a rough estimation of thecorrosion current densities $\left(j_{\text {corr }}\right)$. The numerical values of the corrosion kinetic parameters $b_{\mathrm{c}}, b_{\mathrm{a}}, j_{\text {corr }}$ and $\mathrm{E}_{\text {corr }}$, obtained by fitting experimental data, are shown in figure 4. The numerical values of thecorrosion current densities determined for untreated alloy specimens is $41.2 \mu \mathrm{A} \mathrm{cm}^{-2}$ and for coatingHAp films formed on $\mathrm{Mg}$-alloy for 180 $\min$ at $-2 \mathrm{~V}$ is $0.1 \mu \mathrm{A} \mathrm{cm}^{-2}$. 


\subsection{Characterization of HAp coating}

The Mg-alloy coated with electrodeposited HAp coating was characterizes by FTIR spectra.Electrodeposition was performed at $-2.0 \mathrm{~V}$ for 3 h.Figure 5 shows a FTIR spectrum of $\mathrm{Mg}$-alloy substrate coated by electrodeposited HApfilm that was subsequently alkali treated. A strong $\vee 3 \mathrm{PO}_{4}{ }^{3-}$ vibration band, associated with the internalmodes of $\mathrm{PO}_{4}{ }^{3-}(\mathrm{P}-\mathrm{O}$ asymmetric stretching vibrations $)$, are observed inside the frequency range fromca. $1000 \mathrm{~cm}^{-1}$ to $1100 \mathrm{~cm}^{-1}$ at $1009 \mathrm{~cm}^{-1}$ and $1088 \mathrm{~cm}^{-1}$. The $v 3$ asymmetric P-O stretchingmode is triply degenerate in the free phosphate ion, but this mode is resolved into at least two distinctpeaks in crystalline hydroxyapatite.

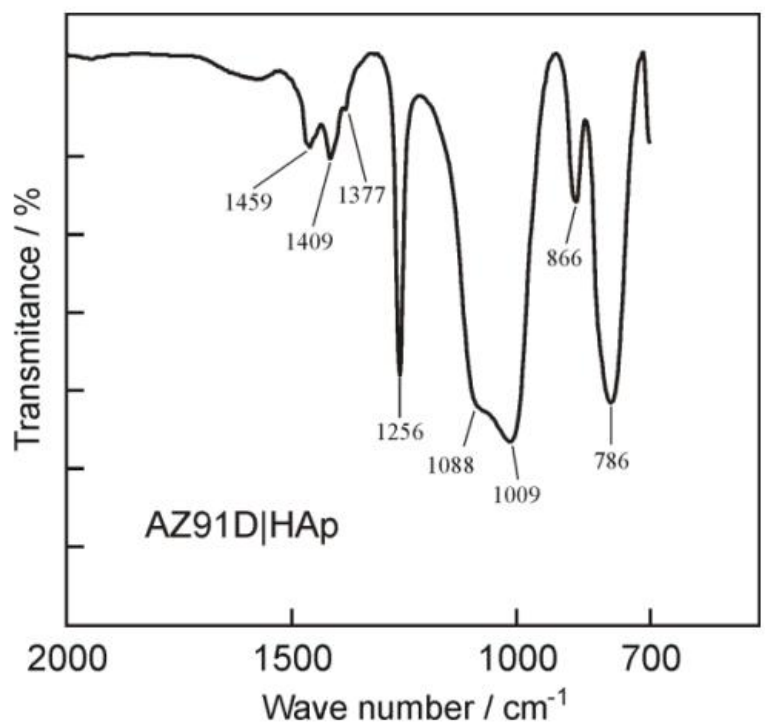

Figure 5. FTIR spectra of Mg-alloy coated with electrodeposited HAp

Hydroxyapatite was observed from two v3 abnds become increasingly resolved the crystallinity from the figure 5. In our infraredspectrum, the two $v 3$ bands are fine- resolved, which indicates that the coating is crystalline. The peaks at 1459,1409 and $1337 \mathrm{~cm}^{-1}$ are due to the presence of carbonate ions in the hydroxyapatite structure. It is well known that carbonate, generated from reaction ofatmospheric $\mathrm{CO} 2$ with aqueous solutions, readily substitutes for phosphate ions (B-type incorporation;i.e., $\mathrm{CO}_{3}{ }^{2-}$ for $\mathrm{PO}_{4}{ }^{3-}$ substitutions) in the crystal structure of hydroxyapatite. The introduction ofthese different ions was beneficial to the biocompatibility because of natural bone tissue also containedMg ${ }^{2+}, \mathrm{Na}^{+}, \mathrm{HPO}_{4}{ }^{2-}$ and $\mathrm{CO}_{3}{ }^{2-}$ which gives an additional advantage because it leads to an enhancedosseointegration.

\subsection{Chemical deposition of hydroxyapatite}

When it comes to light metals, such as $\mathrm{Al}$ and $\mathrm{Mg}$ that have surfaces with mesoporousmorphology, the alternative immersion method (AIM) can be used to efficiently deposit synthetic HAp. AIM method is a strikingly simple method to apply HAp coatings to a surface schematicallyoutlined in Figure 5. In the present approach, the specimens were exposed to 20 cycles of alternatingimmersion in saturated $\mathrm{Ca}(\mathrm{OH})_{2}$ and $0.02 \mathrm{M}$ $\mathrm{NH}_{4} \mathrm{H}_{2} \mathrm{PO}_{4}$. The holding time in each solution was 1 minat room temperature. Between each soaking step and after each cycle, the samples were rinsed inultrapure water for $1 \mathrm{~min}$. Finally, the samples were dried by nitrogen gas. After coating with HAp by AIM barrier properties of coating on the Mg-alloy surface wereinvestigated by EIS. As the shape of spectra is identical to those of fitted withthe same EEC.

\section{Conclusion}

Electrodeposition method was used to modify/increase the bioactivity and biocompatibility the Mgalloy surfacewith hydroxyapatite film. Brushite film and film of a $\beta$-TCP was deposited on Mg-alloy surface and converted into hydroxyapatite (HAp) via an acid-base reaction. Corrosion was tested in Hanks' solution and found that Mg-alloy modified with hydroxyapatite has a higher corrosion resistance in comparison to the unmodified Mg-alloy. The protecting efficiency of HAp increases with the increasing deposition time to obtaina thicker and a more compact coating.By providing higher polarization resistance values in comparison to the surface film by immersion method, electrodeposition method was superior. FTIR was implemented to identify the chemical groups ofHAp coating on Mg-alloy confirmed the presence of the thick uniform layer of hydroxyapatite. Hydroxyapatitecoated Mg-alloy alloy has good potential for use in medicine, because the HAp films has a goodbioresorption. 


\section{References}

[1] L. Wang, J. Chen, H. Watanabe, Y. Xu, M. Tamura, Y. Nakagawa, et al., Catalytic performance and characterization of Co-Fe bcc alloy nanoparticles prepared from hydrotalcite-like precursors in the steam gasification of biomass-derived tar, Appl. Catal. B Environ. 160-161 (2014) 701-715. doi:10.1016/j.apcatb.2014.06.021.

[2] S. Kumagai, J. Alvarez, P.H. Blanco, C. Wu, T. Yoshioka, M. Olazar, et al., Novel Ni-Mg-Al-Ca catalyst for enhanced hydrogen production for the pyrolysis-gasification of a biomass/plastic mixture, J. Anal. Appl. Pyrolysis. 113 (2015) 15-21. doi:10.1016/j.jaap.2014.09.012.

[3] S.T. Jiang, J. Zhang, S.Z. Shun, M.F. Chen, The formation of FHA coating on biodegradable Mg-Zn-Zr alloy using a two-step chemical treatment method, Appl. Surf. Sci. (2015). doi:10.1016/j.apsusc.2015.12.087.

[4] E.C. Meng, S.K. Guan, H.X. Wang, L.G. Wang, S.J. Zhu, J.H. Hu, et al., Effect of electrodeposition modes on surface characteristics and corrosion properties of fluorine-doped hydroxyapatite coatings on Mg-Zn-Ca alloy, Appl. Surf. Sci. 257 (2011) 4811-4816. doi:10.1016/j.apsusc.2010.12.073.

[5] Z. Yang, J.P. Li, J.X. Zhang, G.W. Lorimer, J. Robson, REVIEW ON RESEARCH AND DEVELOPMENT OF MAGNESIUM ALLOYS, Acta Metall. Sin. 21 (2008) 313-328. doi:10.1016/S1006-7191(08)60054-X.

[6] L. Wu, J. Dong, W. Ke, Potentiostatic deposition process of fluoride conversion film on AZ31 magnesium alloy in 0.1M KF solution, Electrochim. Acta. 105 (2013) 554-559. doi:10.1016/j.electacta.2013.04.161.

[7] Z. Grubač, M. Metikoš-Huković, R. Babić, Electrocrystallization, growth and characterization of calcium phosphate ceramics on magnesium alloys, Electrochim. Acta. 109 (2013) 694-700. doi:10.1016/j.electacta.2013.07.095.

[8] W.A. Monteiro, The Influence of Alloy Element on Magnesium for Electronic Devices Applications - A Review, in: Light Met. Alloy. Appl., 2014.

[9] F. Gong, J. Shen, R. Gao, X. Xie, X. Luo, Enhanced corrosion resistance of magnesium alloy by a silane-based solution treatment after an in-situ formation of the $\mathrm{Mg}(\mathrm{OH}) 2$ layer, Appl. Surf. Sci. 365 (2016) 268-274. doi:10.1016/j.apsusc.2016.01.028.

[10] S. V Dorozhkin, Calcium orthophosphate coatings on magnesium and its biodegradable alloys., Acta Biomater. 10 (2014) $2919-34$. doi:10.1016/j.actbio.2014.02.026.

[11] H.X. Wang, S.K. Guan, X. Wang, C.X. Ren, L.G. Wang, In vitro degradation and mechanical integrity of Mg-Zn-Ca alloy coated with Ca-deficient hydroxyapatite by the pulse electrodeposition process., Acta Biomater. 6 (2010) 1743-8. doi:10.1016/j.actbio.2009.12.009.

[12] L. WANG, X. LI, C. WANG, L. WANG, Z. CAO, Effects of cooling rate on bio-corrosion resistance and mechanical properties of Mg-1Zn-0.5Ca casting alloy, Trans. Nonferrous Met. Soc. China. 26 (2016) 704-711. doi:10.1016/S1003-6326(16)64182-1.

[13] I.S. Rončević, Z. Grubač, M.M. Huković, Electrodeposition of Hydroxyapatite Coating on AZ91D Alloy for Biodegradable Implant Application, Int. J. Electrochem. Sci. 9 (2014) 5907-5923.

[14] J. Zhang, C. Dai, J. Wei, Z. Wen, S. Zhang, C. Chen, Degradable behavior and bioactivity of micro-arc oxidized AZ91D Mg alloy with calcium phosphate/chitosan composite coating in m-SBF., Colloids Surf. B. Biointerfaces. 111 (2013) $179-87$. doi:10.1016/j.colsurfb.2013.05.040.

[15] Z. Cheng, J. Lian, Y. Hui, G. Li, Biocompatible DCPD Coating Formed on AZ91D Magnesium Alloy by Chemical Deposition and Its Corrosion Behaviors in SBF, J. Bionic Eng. 11 (2014) 610-619. doi:10.1016/S1672-6529(14)60072-X.

[16] L. Zhang, L. Li, Z.-M. Dang, Bio-Inspired Durable, Superhydrophobic Magnetic Particles for Oil/Water Separation, J. Colloid Interface Sci. 463 (2015) 266-271. doi:10.1016/j.jcis.2015.10.065.

[17] M.K. Kulekci, Magnesium and its alloys applications in automotive industry, Int J Adv Manuf Technol. (2015) 851-865. doi:10.1007/s00170-007-1279-2.

[18] C. Wu, Z. Wen, C. Dai, Y. Lu, F. Yang, Fabrication of calcium phosphate/chitosan coatings on AZ91D magnesium alloy with a novel method, Surf. Coatings Technol. 204 (2010) 3336-3347. doi:10.1016/j.surfcoat.2010.03.045.

[19] M. Razavi, M. Fathi, O. Savabi, D. Vashaee, L. Tayebi, In vivo assessments of bioabsorbable AZ91 magnesium implants coated with nanostructured fluoridated hydroxyapatite by MAO/EPD technique for biomedical applications., Mater. Sci. Eng. C. Mater. Biol. Appl. 48 (2015) 21-7. doi:10.1016/j.msec.2014.11.020.

[20] M.-J. Wang, S.-C. Chao, S.-K. Yen, Electrolytic calcium phosphate/zirconia composite coating on AZ91D magnesium alloy for enhancing corrosion resistance and bioactivity, Corros. Sci. 104 (2016) 47-60. doi:10.1016/j.corsci.2015.11.029.

[21] G. LIU, S. TANG, C. WANG, J. HU, D. LI, Formation characteristic of Ca-P coatings on magnesium alloy surface, Trans. Nonferrous Met. Soc. China. 23 (2013) 2294-2299. doi:10.1016/S1003-6326(13)62731-4.

[22] M. Li, Y. Cheng, Y.F. Zheng, X. Zhang, T.F. Xi, S.C. Wei, Surface characteristics and corrosion behaviour of WE43 magnesium alloy coated by SiC film, Appl. Surf. Sci. 258 (2012) 3074-3081. doi:10.1016/j.apsusc.2011.11.040.

[23] J.-J. Wang, K. Yang, Z.-L. Xu, C. Fu, L. Li, Z.-K. Zhou, Combined methodology of optimization and life cycle inventory for a biomass gasification based BCHP system, Biomass and Bioenergy. 67 (2014) 32-45. doi:10.1016/j.biombioe.2014.03.026.

[24] E.C.S. Rigo, A.O. Boschi, M. Yoshimoto, S. Allegrini, B. Konig, M.J. Carbonari, Evaluation in vitro and in vivo of biomimetic hydroxyapatite coated on titanium dental implants, Mater. Sci. Eng. C. 24 (2004) 647-651. doi:10.1016/j.msec.2004.08.044.

[25] Y. Ren, H. Zhou, M. Nabiyouni, S.B. Bhaduri, Rapid coating of AZ31 magnesium alloy with calcium deficient hydroxyapatite using microwave energy., Mater. Sci. Eng. C. Mater. Biol. Appl. 49 (2015) 364-72. doi:10.1016/j.msec.2015.01.046.

[26] Y. Xu, X. Zheng, X. Hu, Y. Yin, T. Lei, Preparation of the electroless Ni-P and Ni-Cu-P coatings on engine cylinder and their tribological behaviors under bio-oil lubricated conditions, Surf. Coatings Technol. 258 (2014) 790-796. doi:10.1016/j.surfcoat.2014.07.079.

[27] C.F. Dunne, G.K. Levy, O. Hakimi, E. Aghion, B. Twomey, K.T. Stanton, Corrosion behaviour of biodegradable magnesium alloys with hydroxyapatite coatings, Surf. Coatings Technol. 289 (2016) 37-44. doi:10.1016/j.surfcoat.2016.01.045.

[28] L. Chang, L. Tian, W. Liu, X. Duan, Formation of dicalcium phosphate dihydrate on magnesium alloy by micro-arc oxidation coupled with hydrothermal treatment, Corros. Sci. 72 (2013) 118-124. doi:10.1016/j.corsci.2013.03.017. 